Defining the demand side of VET:

Industry, enterprises, individuals and regions

\author{
Stephen Billett \\ Faculty of Education \\ Griffith University \\ NATHAN 4111 \\ Australia
}

Billett S (2000) Defining the demand side of VET: Industry, enterprises, individuals and regions.

Journal of Vocational Education and Training, 50 (1) 5-30 


\section{Defining the demand side of VET: Industry, enterprises, individuals and regions}

The need for vocational education to respond to demand-side factors has become a key policy goal for vocational education in Australia. However, what comprises the demand side has not been critically appraised. Assumptions that only industry and enterprises comprise the demand-side are questioned by the legitimate claims for inclusion by regions and individuals. Taking this more inclusive definition of the demand-side of vocational education, the outcomes of a study are reported that investigated the changing relationships between industry and enterprises. It also mapped the needs of the four client groups. Identified are both commonality and difference in these needs, some of which are not readily reconcilable within an enterprise or industry-led vocational education system. Means for reconciling the needs of the client groups within curriculum development are discussed, as are some supply-side considerations.

\section{$1 \quad$ Introduction}

A current imperative is for vocational education to be highly responsive to 'demand-side' requirements. Yet what comprises the demand-side, at this time, has not been made explicit by government or what passes as its current composition appraised critically. Moreover, how vocational education should respond to conflicting demand-side requirements has yet to be clarified. Many working in the Australian vocational education sector hold that it has already been highly responsive to 'industry' over the past decade, much to the detriment of educational principles and values, and the narrowing of teachers' role (Billett et al in press). Given the degree of mandation by government to meet industry needs in the form of prescriptive curriculum and accreditation processes, those in the sector might wonder what have they been responsive to over the last decade, if it was not what government had designated as the demand-side. However, now it seems the emerging tensions between the demands of 'industry' and enterprise needs are transforming the goals for and purposes of vocational education. Vocational education is now asked to be responsive to enterprise needs. This paper defines the demand side of vocational education more inclusively and comprehensively by adding the needs of regions and individuals to those of industry and enterprises. Using the analysis of an investigation that aimed to identify the requirements of VET for these client groups, thereby making their needs more comprehensive. The paper puts aside the argument for supply-side consideration, and criticism of the concept of the demand-side equation. Instead, it attempts to take the demand-side on its own terms, be more inclusive in its categories of client groups and comprehensive in responding to their needs.

\section{Demand-side of vocational education}


The need for vocational education provisions to be driven by demand requirements, more than supplyside factors, has become a key policy goal for vocational education in Australia (Allen Consulting Group 1994a, 1994b, ANTA 1996, Robinson \& Kenyon 1998). That is, this education sector is to be shaped far more by the identified needs of clients than a consideration of existing programs and infrastructure or of those interests that are not direct clients, such as educators. They key purposes of this policy goal is to enhance sponsorship of and improve both the participation in and quality of vocational education provisions. These goals have been fundamental to the training reform in Australia over the last decade.

However, such imperatives hardly seem new. Over the past decade, the vocational education sector in Australia has been highly responsive to the demands of 'industry'. Industry here is taken as those bipartite groups who speak on behalf of employers and employees within a particular industry grouping. The vocational education sector has had little option but to respond to these needs in the last decade. At both the state and national level, industry advisory bodies received government endorsement for their leadership role in that industry sector (Dawkins 1988) and authority to formulate the intents (aims, goals and objectives) and content of national core curriculum documents, framed by national industry competency standards (National Training Board 1992). Teachers were excluded from involvement in the process of developing the intents for and content of courses. Moreover, to secure fidelity to these industry-based prescriptions, accreditation and registration frameworks and procedures were implemented (VEETAC 1992). These procedures aimed to manage the quality of the courses and their adherence to competency based models of instruction and assessment, through administratively mandated means. Such frameworks and procedures were unconcerned whether the teachers who were to enact the curriculum believed that such approaches were educationally sound, appropriate or likely to develop the skillfulness desired by government sponsors. Instead teachers' role was to implement what industry wanted with fidelity. The process has been dominated by industry and industrial relation concerns rather those of individuals or other interests. However, in recent times there has been a shift in the focus of government attention from national industrial awards to individual workplace agreements (Callus 1994, Guthrie \& Barnett 1996). Now, it seems particular enterprise needs (particularly those of large enterprises) are becoming the key targeted group to whom VET has to be responsive. The national industry standards and core curriculum that have dominated the last decade of vocational education are seen as being increasingly redundant in the face of changes in the current political and industrial environment (Billett, Cooper, Hayes \& Parker, 1997). 
However, what comprises the 'demand-side' of vocational education is not sufficiently accounted for by considering only the changing relationships between the two groups that have been the focus of most attention: enterprises and industry. Instead, a broader set of interests warrant inclusion, and their needs acknowledged and included in deliberations about the intent and content of vocational education. Firstly, regions have been recognised as having needs that cannot be understood or readily met by highly centralised processes and prescriptions (Schofield 1996). Throughout Australia there are federally funded regional development boards which acknowledge significant regional differences and the need for local inputs and planning. These differences are important for vocational education (Billett et al 1997). In the United Kingdom the need for regional planning has been accomodated with decentralisation in decision-making being practiced (Employment Department 1993). In particular, the policy focus is on promoting an integrated approach to delivery of programs at the local level through regional agencies. This approach acknowledges that, as has been recognised in Australia (Schofield 1996), regional goals and needs are unlikely to be uniform, and that local planning and needs assessment are required because centralised planning processes are not sensitive enough to determine local need.

In addition, beyond regions, individuals are now also being acknowledged as a group who are making a significant contribution not only to their own, but also to the nation's social and economic development (Chapman 1997). As students within vocational education, individuals are expected to contribute more both directly and indirectly to their own education. Not only are they increasingly making greater contribution to the cost of that education, but are electing to enroll in longer duration courses, thereby giving more of their time with its accompanying economic value (State Training Board (STB) 1995). It is also worth noting the contrast between the increased commitment that individuals are making to their own development, which has a broader social and economic dividend, to the reduced commitment that enterprises are currently making to vocational education. So, individuals with their aspirations and needs can also legitimately claim to comprise part of the demand-side of VET. However, as has been argued elsewhere (Billett, et al, 1997) like regions individuals are a client group whose voice is not currently being heard and who cannot be confident that its needs are being represented as part of current decision-making processes. This seems curious because current policy documents place individuals at the forefront of goals for vocational education. The Australian National Training Authority’s (ANTA) mission statement specifically refers to explicitly to individuals: 'To ensure that the skills of the Australian labour force are sufficient to support internationally competitive commerce and industry and to provide individuals with opportunities to optimise their potential.'(ANTA 1998:preface). Yet, how can their potential be fully met unless their needs are understood and taken into account. Even taking the narrow view, that 
individuals here are only being seen in terms of how they can contribute to enterprise performance, would warrant a consideration of how this contribution can best be made. Yet there is little evidence that efforts to understand these needs are being made in the current industry and enterprise focussed vocational education system.

Together, the inclusion of new demands (individuals and regions) and transforming interests (industry vs enterprises) represent significant challenges for policy and practice within vocational education. If, as government policy claims, vocational education is to be focussed on meeting demand-side requirements, the needs of all those interests that comprise the demand-side should be identified and met. If the needs of only some of those interests are taken into account, the demand-side is not being met. Therefore, having proposed that the demand-side for vocational education comprises these four groups, and taken government policy at its word, it is necessary to understand the needs of these groups, and identify compatibility and inconsistency in those needs. To determine the scope and qualities of these needs, an investigation was conducted to examine the relationships between the two current components of the demand side (industry and enterprise) and identify the needs of the four client groups. The procedures used to gather data and the outcomes of the analyses of some of that data are presented in the following sections.

\section{Procedures}

The research design comprised an investigation of two fields of vocational activity in three regions within Australia. The selected procedures aimed to elicit and analyse data associated with the complex of factors which influenced how best VET provisions can be implemented to meet the needs of the four client groups (industry, enterprises, regions and individuals) which together comprised the demand-side of VET.

\subsection{Phase One - Identifying and accessing the fields}

Initially, two industry sectors were identified that reflected both existing and emerging vocational education provisions. These were respectively, clerical and food processing. The reason to select an existing and emerging provision was to investigate a sector that has a long-standing relationship with vocational education as well as those currently being developed in an emerging industry sector. This arrangement provided the potential to understand whether a provision founded in the supply-side (Clerical) differed markedly in terms of provisions than an emerging one being shaped by demandside requirements (Food processing). To reflect the diversity of regions within Australia, three different kinds of regions were identified and selected. These were: (i) a metropolitan region; (ii) a 
provincial centre; and (iii) a remote rural centre. These regions were distributed across four Australian states (a twin-town sitting across state borders comprised one region). Key informants from each of the client groups were identified and contacted in the three regions. This process was aided by the appointment of a co-ordinator in each region who was able to identify and provide access to informants.

\subsection{Phase Two - Mapping the fields}

Consultations were extensive and combinations of data gathering strategies were adopted that most suited the informant group. Interviews were selected to gather data from Industry, Enterprise and Regional representatives. Focus groups and surveys were selected for informants representing prospective, current and past students (Individuals). In each region, 10 enterprises were interviewed across the two industry sectors, up to 10 community informants, and industry representatives for both industry sectors. Cohorts of students were engaged in focus groups activities and surveys. The items used in the interviews, surveys and focus groups were designed to gather data about the shift in focus to an enterprise based system and the changing values resulting from this change. Also, data was collected about the needs of each group in terms of the quality of existing provisions and what was desired by these groups - ('what is' versus 'what should be'). The data comprises, in the main, verbal accounts. Respondents were asked for instances to validate their responses and avoid their characteristisation as 'mere opinion'. As this investigation focussed on identifying needs and how existing provisions were meeting those needs, perceptions, values and self-interest necessarily colour the contributions. Additional data was drawn from the TAFE Graduate Destination Survey (GDS) (NCVER 1997), about the views of students who had attended the four Technical and Further Education (TAFE) ${ }^{1}$ institutes in the three regions.

\subsection{Phase Three - Identifying transformations and consequences for VET policy and practice}

An initial qualitative analysis of the data was undertaken to identify sets of issues, particular needs and tentative recommendations. The analysis was undertaken by producing a detailed case study for each region that aggregated all the data for that region. Much of the analysis comprised identifying the needs of the groups and to what degree these were consistent with those of other groups.

\subsection{Phase Four - Refining the analysis with key VET client groups}

The case studies developed in Phase Three were returned to representatives of the key client groups in the three regions in order to order to gauge their responses and refine the findings. From these case 
studies, the data from the case studies were aggregated and analysed as one set. This aggregated data is used in this paper.

\section{Data analyses}

This section reports the analysis of the aggregated data from the regional case studies. The following section provides a synthesis of the data across the regions and industries comparing how currently the needs of the client groups are being met ('what is') with how they should be met ('what should be'). Table 1, which provides summaries of the aggregated data, is divided into two sections. One section summaries the data on the 'processes' of vocational education provisions and the other summarises data on 'outcomes'. In the left-hand column, statements of need are presented. These summaries have been synthesised from the interviews, focus group and survey data. To the right of this column are four others indicating whether or not each client group (i.e. industry, enterprises, individuals and regions) identified this need. For example, all four groups identified 'Having competent teachers', whereas 'External auditing and reliability of assessment' was identified only by Industry respondents. In the next two columns, summaries of the data indicating ways in which these needs are reported as either being met or not being met are presented. In parenthesis, after each statement about how a need is being secured, the frequency by which informants from each client group supported these views is indicated. However, these frequencies are merely illustrative and not meant to represent any quantitative analysis.

Each client group's needs and the way these are being realised are reported and discussed in turn. The client groups' needs in terms of processes and outcomes of VET provisions are identified, followed by a summary of the evidence about how these expectations are being met and are not being met.

\subsection{Industry}

Industry needs, in terms of processes, in both industry sectors were identified as being associated with the currency of, and flexibility in vocational education provisions, the competence of the teaching staff, and the infrastructure to provide quality delivery. Flexibility refers to access, meeting the requirements of both small and large enterprises and with negotiation, input, and decision-making occurring at the local rather than at the national level. However, in response to local decision-making and negotiation it was suggested that Industry Training Advisory Bodies (ITABs) -- peak industry bodies -- should still identify needs for the industry. Consistent with this, it was suggested that flexibility at the local level should remain managed through the use of external auditing to assist with

\footnotetext{
${ }^{1}$ In one state, the acronym TAFE refers to Training and Further Education
} 
adherence to national standards and certification. So within industry, there was residual interest in the processes of vocational education remaining within a centralised industry framework. This sentiment was also reflected in a call for reliability of assessment. However, there was considerable concession to local enterprise needs being met. 
Table 1: Comparing client groups needs and how these are being met

\begin{tabular}{|c|c|c|c|c|c|c|}
\hline $\begin{array}{l}\text { Needs associated with } \\
\text { processes of VET provisions }\end{array}$ & I & $\mathrm{E}$ & $\mathrm{C}$ & $\mathrm{S}$ & How those needs are being met & How those needs are not being met \\
\hline $\begin{array}{l}\text { Courses which are current, } \\
\text { relevant, cost-effective and } \\
\text { flexible }\end{array}$ & $\checkmark$ & $\checkmark$ & $\checkmark$ & $\checkmark$ & $\begin{array}{l}\text { Traineeships permit greater access (1C), } \\
\text { Operator level courses flexible varied and } \\
\text { accessible (8I, 8E), TAFE excellent (3E), } \\
\text { good (6C, adequacy of provision (3E) Self } \\
\text { pacing useful (2S), Negotiated learning } \\
\text { arrangements (2S), Well served by } \\
\text { educational institutions (8C), Meeting needs } \\
\text { well (8I) }\end{array}$ & $\begin{array}{l}\text { Need to access individual modules (1E), Inadequacies of distance } \\
\text { provisions (E3, 6S), Greater access to teachers (1E, 1C), Materials not } \\
\text { ready or well prepared (2S), Inconsistency in TAFE provisions (2E), } \\
\text { Duplication of content (4S), Practical learning (1C), Pre-testing of skills } \\
\text { to advance credit (1S), }\end{array}$ \\
\hline Having competent teachers & $\checkmark$ & $\checkmark$ & $\checkmark$ & $\checkmark$ & $\begin{array}{l}\text { Flexible and accommodating (8C, ) supportive } \\
\text { (2C), } \\
\text { Graduate Destination Survey, }\end{array}$ & Teachers expertise lacking (2I, 3E) \\
\hline $\begin{array}{l}\text { Having mechanism which } \\
\text { addressed enterprise needs } \\
\text { within industry frameworks }\end{array}$ & $\checkmark$ & & & & Separate course for each sector (I2), & $\begin{array}{l}\text { Differentials in training among industries (1C), TPs eroding industry } \\
\text { framework (1I), Non-completion of certificates in work-based programs } \\
(4 \mathrm{I})\end{array}$ \\
\hline $\begin{array}{l}\text { Infrastructure to provide } \\
\text { quality courses }\end{array}$ & $\checkmark$ & & & $\checkmark$ & $\begin{array}{l}\text { Useful integration of on-off job components } \\
\text { (E2) }\end{array}$ & Lack of integration between on and off job components (3E), \\
\hline $\begin{array}{l}\text { External auditing and } \\
\text { reliability of assessment. }\end{array}$ & $\checkmark$ & & & & & Failure of quality control (2I), \\
\hline $\begin{array}{l}\text { Courses customised to } \\
\text { enterprise needs }\end{array}$ & & $\checkmark$ & & & $\begin{array}{l}\text { Addressing enterprise (6I, 5E), O-t-j } \\
\text { assessment (1I) and learning (8E, 7S), } \\
\text { Integrated with work activities (6S), Group } \\
\text { learning supported (4S) }\end{array}$ & $\begin{array}{l}\text { Not enough customisation (4I, 7E ) and variation in success (4E), } \\
\text { Teamwork (1E), TAFE not aware of (3C ) or addressing enterprise needs } \\
\text { (3C), lack of alignment between VET and industry (2I), Lack of genuine } \\
\text { options (2E), Unavailability of specific provisions (4E), }\end{array}$ \\
\hline $\begin{array}{l}\text { Courses addressing individual } \\
\text { (employees) needs }\end{array}$ & & $\checkmark$ & $\checkmark$ & $\checkmark$ & Addressing student needs(4I,6S) and & $\begin{array}{l}\text { Cost inhibits access (1S), Not addressing needs of learners (1I, 3E, 1S), } \\
\text { Short course suit enterprise more than learners (1E), Demands on self } \\
\text { (1S), workplace colleagues (3S), Not enough indigenous teachers (1C), } \\
\text { Non-completion of certificates in work-based programs (4I) }\end{array}$ \\
\hline Capacity to offer in-house & & $\checkmark$ & & & & \\
\hline $\begin{array}{l}\text { High levels of interaction with } \\
\text { providers }\end{array}$ & & $\checkmark$ & & & $\begin{array}{l}\text { Collaboration useful (E4), VET in schools and } \\
\text { links with TAFE (2C) }\end{array}$ & \\
\hline Competition among providers. & & $\checkmark$ & & & Growth of private providers (1C) & Too many providers dilute quality (2E) \\
\hline
\end{tabular}




\begin{tabular}{|c|c|c|c|c|c|c|}
\hline $\begin{array}{l}\text { Needs associated with } \\
\text { outcomes of VET provisions }\end{array}$ & I & $\mathrm{E}$ & $\mathrm{C}$ & $\mathrm{S}$ & How those needs are being met & How those needs are not being met \\
\hline $\begin{array}{l}\text { Consultation with and } \\
\text { interaction among providers } \\
\text { (teachers) and local } \\
\text { community }\end{array}$ & & & $\checkmark$ & & & Lack of promotion of VET in community (1C) \\
\hline Responsive to local needs & & & $\checkmark$ & & Addressing local (1C) needs & $\begin{array}{l}\text { Geographical dispersion (7C), Young people have to leave area (1C), } \\
\text { Distance to travel (2S), Too many providers dilute quality (2E), Not } \\
\text { enough VET in schools (2C) }\end{array}$ \\
\hline $\begin{array}{l}\text { Skilled workforce (flexible, } \\
\text { self-directed, safe, } \\
\text { certificated) }\end{array}$ & $\checkmark$ & & & & $\begin{array}{l}\text { Theoretical understanding (E4), Certification } \\
\text { (5S), Transferable skills (2S) }\end{array}$ & $\begin{array}{l}\text { Lack of underpinning knowledge (1I), Not taught to learn how to learn } \\
\text { (1S), }\end{array}$ \\
\hline $\begin{array}{l}\text { Wider participation, } \\
\text { especially by small enterprises }\end{array}$ & $\checkmark$ & & $\checkmark$ & & Incentives subsidise training (1E) & $\begin{array}{l}\text { Delivery to small and remote businesses (3I), Current funding inhibiting } \\
\text { small business participation (1E), Participation of small business (3C), } \\
\text { Employers not participating in ELT (7C) or training casual workers (1C) }\end{array}$ \\
\hline Career pathways for workers. & $\checkmark$ & & & & & \\
\hline $\begin{array}{l}\text { Specific job-ready skills } \\
\text { (technical, organisational, } \\
\text { personal and attitudinal) }\end{array}$ & & $\checkmark$ & & & $\begin{array}{l}\text { Basic skills learnt at TAFE (12E), Improves } \\
\text { confidence and skills (2S) }\end{array}$ & Beyond technical needs - other less measurable outcomes (3E) \\
\hline $\begin{array}{l}\text { Measurable outcomes relevant } \\
\text { to improving business }\end{array}$ & & $\checkmark$ & $\checkmark$ & & & \\
\hline Accredited courses & $\checkmark$ & $\checkmark$ & $\checkmark$ & $\checkmark$ & Certification (5S) & \\
\hline $\begin{array}{l}\text { Learning new and updating } \\
\text { knowledge }\end{array}$ & & & & $\checkmark$ & Focus on learning (E1) & \\
\hline $\begin{array}{l}\text { Realising employment, self- } \\
\text { employment, career goals }\end{array}$ & & & $\checkmark$ & $\checkmark$ & TAFE viewed positively by job seekers (2C), & $\begin{array}{l}\text { Course levels discourage access (2C, 3S), Accessing work placements } \\
\text { (1S), Cost inhibits access (1S), Longer and more through period of initial } \\
\text { preparation (6S), Lack of information (1S), Not enough workplace } \\
\text { training available (1C), courses being accessed by students with no other } \\
\text { options (1I), workplace-based provisions secondary to production (4I), }\end{array}$ \\
\hline $\begin{array}{l}\text { Pathways to higher levels of } \\
\text { education and promotion. }\end{array}$ & & & & $\checkmark$ & & Focus on ELT, rather than up-skilling (3I), \\
\hline $\begin{array}{l}\text { Enhanced sponsorship of ELT } \\
\text { by enterprises; }\end{array}$ & & & $\checkmark$ & & & Current funding inhibiting small business participation (1E) \\
\hline
\end{tabular}


The outcomes desired by industry representatives were, at the enterprise level, for skilled workers whose attributes include being flexible, safe, self-directed and productive. VET provisions supporting these needs are to be relevant and applicable to the enterprise. At the industry level, accredited, current and relevant courses, which are the product of industry consultation, leading to improved participation by small businesses, and career paths and certification for industry workers were desired as outcomes. So for these respondents there remained an important role for 'industry’ to provide quality and reliability measures at the national level.

Industry informants emphasised how the current provisions are now being offered in ways meeting enterprise needs through flexibility of students and access. In particular, strands in the Food Processing sector permit relevance in course provisions. In the clerical sector, it was claimed, the provisions meet the needs of both school leavers and older workers returning to work.

Current VET provisions were failing to meet industry needs in terms of there not being enough enterprise customisation or meeting the needs of small and remote businesses. Only two out of a possible 16 informant questioned teachers' technical expertise. There were also concerns from the clerical sector about the emphasis on pre-vocational rather than more advanced courses and the belief that many students were accessing these courses and participating at a high level because of a lack of choice or because of unemployment. Students who could not find employment continued to work through higher levels of certificates despite lacking employment experience. Industry concerns also included the priority given to workplace-based provisions and the high incidence of non-completion of the Certificate of Food Processing, with enterprises only sponsoring modules essential to their purposes.

Industry representatives proposed how individuals and enterprise needs were being met through industry frameworks. These perspectives may represent self interest in maintaining and reflecting an interest in the legacy of work at the industry level over the last decade. Concerns about structures of courses (an industry responsibility) and the inadequacy of work-based provisions in meeting both individuals and enterprise needs were also advanced. More customisation was called for and solutions to provisions for enterprises which are small and/or remote. 


\subsection{Enterprises}

Enterprise concerns about processes were associated with provisions and quality of courses. Access to flexible local provisions either through TAFE or developing the capacity within enterprises themselves were identified as key needs. Provisions focussed tightly on enterprise needs, including interesting and motivating their staff. These courses were to be presented by teachers whose content knowledge was current, had an intimate knowledge of the enterprises' needs and were exemplary teachers. Enterprise representatives also stated the need for a competitive training market to secure best value and quality in these provisions. In addition, the capacity to assess employees' progress and evaluate the utility of the programs is also required.

In terms of outcomes, Enterprises wanted individuals with job-ready skills that have technical, attitudinal, personal and organisational dimensions. These outcomes need to be linked intimately to the specific tasks undertaken by the enterprise and contributing directly to its overall goal of improved measurable business outcomes. Two levels of customisation were demanded: firstly to customise the particular content to their needs and also for customisation within the work practice. So to take two examples, clerical workers in a retail setting not only had to have clerical knowledge but also had to undertake retail tasks during busy periods. In a similar way, clerical workers in a hospital had to have skilfulness associated with the patent administrative processes of the hospital and also be quasi health care workers. Enterprises also wanted accredited courses that were the product of wide consultation with industry. As such, currency and relevance to the enterprise coalesce with industry standards. Yet the degree of customisation required by enterprises is potentially antagonistic to the maintenance of uniform standards, as desired by industry.

There was general acknowledgement of the contribution and flexibility of TAFE in entry-level training, the accommodation of enterprise needs within customised curricula and the worth of collaboration between enterprises and TAFE. In addition, the value of both on and off-job experiences was generally supported. The excellence of the TAFE provision and the ability of TAFE teachers to set up training systems in workplaces were stated by some enterprises. Most eenterprises wanted direct negotiation with providers to achieve their goals. However, these negotiations are largely founded on realising enterprise specific goals and not on establishing collaborative or strategic relationships with providers. 
Typically, most enterprises proposed direct negotiations with providers as being the best way to address their short-term and long term training needs. The focus for these negotiations was for providers to develop an intimate knowledge of enterprise needs in order to customise curriculum. Little recognition of the value of reciprocal arrangements that seek to understand providers' constraints was forthcoming from enterprises. Despite calls for flexibility, enterprise needs of vocational education processes and outcomes were quite rigid, they had to suit their specific needs.

However, in terms of wholly satisfying enterprise needs, the preparation for the specific needs of enterprises were claimed by some not to have gone far enough and be of mixed success. Concerns about the degree of integration between on and off-job provisions were also raised. As with industry respondents, there were concerns about provisions in the workplace. Moreover, the adequacy of distance modes of learning, teachers' knowledge and inconsistency across TAFE's provisions in the workplace were questioned. One enterprise doubted whether employees' needs were best addressed by short enterprise-focused courses. Concerns also included the widening field of providers, opportunities for genuine learning and whether the best methods for learning were being adopted. For example, one viticulture enterprise reported being dismayed by the disparity in the duration of courses offered by both the public and private providers. So, in sum, the focus of many of the enterprise concerns was upon inadequacies of the tailoring of the needs of enterprises and their employees. The most commonly perceived shortcoming was the degree of customisation or tailoring of courses that enterprises believed should occur. Interestingly, some criticism appeared to be fuelled by distaste of TAFE being a publicly funded provider. There were assumptions that neither TAFE nor its teachers were responsive because they were immune from the market. Yet, others reporting genuine efforts at collaboration, were quite unreserved in their support of and respect for the TAFE provisions. Curiously, in almost every instance, where enterprises were critical of TAFE, they also provided positive accounts of performance. It seemed that negative judgements about TAFE provisions were not always wholly supportable by the evidence being proffered.

Overall, enterprise needs were tightly focussed on outcomes associated with their immediate goals and concerns. An outcome that emerged from the enterprise interviews was their frequent lack of a strategic or long term view about the skill needs of their workforces. For instance, despite common knowledge of an impending shortage of tradespersons, due to a decline in apprenticeship numbers, none of the enterprises indicated they intended to increase their 
commitment to apprenticeships. This was despite at least two of the regions having very low portability in its labour force. Hence, the investment in an apprentice would unlikely to be lost to the enterprise or the region. A regional representative with responsibilities for apprenticeships commented that these enterprises believed government would do something if the apprenticeship situation eroded further. If this claim is supportable, and there is evidence that suggest enterprises are not sponsoring entry level training as they have in the recent past (STB 1995). This leads to questions about the wisdom of vesting the leadership role of the vocational education system by enterprises. Their goals appear too inward focussed and short term for such a responsibility.

\subsection{Regions}

The uniqueness of each region's needs that had consequences for vocational education was identified thereby highlighting the requirements for planning at the regional level. Factors that comprised these unique requirements included the:

- type of industries;

- employment opportunities;

- educational provisions;

- demographic factors; and

- goals/needs and structures/identity of each region.

Each of these variables has particular consequences for vocational education provisions in terms of the courses to be offered and needs of students in the course. These variables include, the prospects for structuring relationships with providers, the infrastructure available to support programs, the age, aspirations, previous educational history, English language skills and accessibility of the individuals in the region and how the regional goals coincide with the educational programs. For example, the two non-metropolitan regions had specific goals for industry development. Respondents proposed meeting the uniqueness of regional needs through regional planning. The preferred approach to managing local planning process, was a coordinated approach that could plan for and reconcile the needs of clients at the regional level.

The process needs of the regions consistently focus on consultations and interactions among all client groups and between these groups and providers. Specifically, it was held that the provisions have to identify, understand and meet individuals' needs. The competence of teaching staff was also held to be important. In addition, the maintenance of national curriculum to assist with certification and portability for individuals was commonly acknowledged. 
The desired outcomes of regional representatives included higher levels of sponsorship of training by small business and enhanced participation in apprenticeship-type arrangements by local enterprises. Associated with this were demands that courses be relevant and applicable, meeting the needs of learners, not only in gaining employment but also in the pursuit of careers. Balancing concerns between individuals and enterprises, the community respondents also emphasised the need for vocational education provisions to add value to the enterprise and improve business outcomes. It was commonly proposed that if local enterprises thrived so would the community, as employment and career opportunities would be available for locals. In the two non-metropolitan regions, a concern existed that region's young people would leave search of employment and never return. Hence, courses in the region are required to be accredited, the result of consultation with business, and also be current, relevant and applicable to local enterprises and of sufficient standing and level to offer prospects of career pathways.

The regional informants almost universally expressed satisfaction with the educational provisions and the flexible approach adopted by TAFE in meeting local needs. This satisfaction extended to include particular minority needs such as those of migrants. The view from regional informants was that enterprises' and individuals' needs of the region were being well catered for. Concerns raised by these community informants were most commonly associated with resources to make vocational education more accessible to remote students, those with special needs, and the shortcomings of diversifying resources into large companies or overseas ventures. However, overall, most concerns of regional representatives were about the lack of participation in vocational education and the apparent short-sightedness of local enterprises. Balancing this concern was some evidence of an emerging initiative of loose alliances among small businesses which can be, and in some cases, were being used to organise provisions of vocational education in ways that each enterprise would unable to do independently. This approach has been proposed as a likely means for training within small business (Buttery \& Buttery 1995; Kearns 1995) as it is forged by mutuality of interests and represents something that could be nurtured at the regional level.

So, in sum, regional concerns were focussed on resourcing, the willingness of enterprises to participate and the impact of competition policy on the region as much as criticisms of the adequacy of TAFE or its teachers. The value of TAFE and its teachers was strongly supported and almost universal. 


\subsection{Individuals}

Individuals consistently reporting wanting quality flexible vocational education provisions supported by appropriate infrastructure. These provisions are to comprise well-prepared content, presented by competent, positive and supportive teachers, able to realise individuals' needs. Data from the students' surveys indicates that Practical skills for the job and Good Teachers were also qualities most desired by the students. Outcomes proposed by individuals for their participation in vocational education were mainly employment-related. However, more than being just about gaining employment, they focused on progression, careers and self-employment. To illustrate the kind of responses these respondents provided, the following goal statements are from five prospective clerical course students who were asked what they wanted from the course in a focus group.

- A good job, which is not in a factory and pays well so I can buy a house.

- Partner wants to retire from train driving in 5 years time and drive trucks. She wants to be the bookkeeper for this business.

- Has been in catering for the last 10 years but was made redundant last year. She enjoyed some short computer courses and decided to work her way up the ladder.

- Daughter is now in high school and will need to know how to use computer. It is important that she can show her because daughter has a learning disability.

- Completed a course last year, Cert. in General Ed. for adults, and decided she wanted to do another course. She is new to the region and hopes to meet people and get some work in office admin, even as a volunteer. She has not been in the workforce for 20 years and wants to bring herself up to current standards and get over her fear of computers.

These prospective students have goals that are career-related, strategic and responding to personal and family needs. They are not short term. Also, not all of them fit readily into the kind of goals that industry and enterprise representatives have proposed for vocational education.

Student informants in the focus groups also provided data about the quality of provisions (access, flexibility, attendance patterns, options, integration of experiences) and outcomes (transferable skills, confidence and skills, certification). The survey data reported students valuing access to workplace practice organised through TAFE, certification, and transferability of knowledge learnt within college. The self-paced approach adopted in TAFE was seen to meet the needs of some current and prospective students in the survey. The most commonly proposed response from the on-campus respondents was the support in and convenience of this mode of study. Students reported teachers making themselves and facilities available so that students could gain additional practice on basic skills and the flexibility in time tabling to meet the needs of the students (e.g. family and work commitments). 
Students' dissatisfaction was associated with both workplace-based provisions and those for campus provisions. Concerns about the former include the level of work required, the need for pre-testing to give credit for existing learning, the difficulties with distance provisions, the preparedness and completeness of materials, reliance upon others, the amount of time required and problems imposed by shift work. All of these are significant process problems. Students who were also employees and engaged in work-based learning processes were critical of the tight enterprise focus in their programs. They saw themselves having aspirations not necessarily restricted to their current employment. Despite enterprise sponsorship of their participation in courses, these subjects stated their time and commitment to home based study should reap personal benefits as well as aiding company productivity. Of particular concern, for these students, was that enterprises often only sponsored the modules from courses directly attributable to these needs. Hence, although module completions were high, completion of certificates by employees was not. Compounding the problem was the claim that providers of courses were not always interested or able to provide the balance of the modules to these employers as individual students. Hence, personal aspirations of certification and portable skills were jeopardised.

Concerns from campus-based students were associated commonly with the need for longer periods of preparation and reinforcement of basic skills, the relevance of some material, and accessing teacher time. Of these, the concerns by current students about relevance are most noteworthy. Significantly, when asked how the arrangements had failed to secure their needs, the students responded quite uniformly and with the highest frequencies that the provisions had not failed to meet their needs. Again, this client group praised the quality of the TAFE provisions and the effort made by teachers.

\section{Discussion}

\subsection{Enterprises as the current demand side focus}

It was reported that a shift to a focus on enterprise needs had or was occurring. This was more evident in the one sector (Food Processing) than in the other (Clerical) industry sector Respondents were able cite instances of where this had occurred. However, while vocational education may be responsive to the needs of enterprises, particularly large enterprises, this may result in highly specific learning outcomes, rather than those focussed on the longer term goals of industry and individuals. However, the actual cognitive consequences of learning that is highly specific are not yet fully understood. Indeed, it is increasingly held that all learning is 
situationally specific to the circumstances in which it occurred (Resnick, Pontecorvo \& Saljo 1997). The prospect of transfer is most likely founded on perceived similarity or difference for the application of the knowledge between the circumstances in which the knowledge is learnt and that to which it is to be transferred. This, for instance, is one reason why the transfer of learning in the school room to the workplace may be limited; because the circumstances are quite remote from each other (Rogoff \& Lave 1984). So, until the circumstances that individuals wish to transfer the knowledge to be are known about, it is difficult to predict or judge the likelihood of transfer. This is also true of trying to predict what novel problems are likely to arise in the particular workplace. Also, the prospects for transfer will have idiosyncratic qualities as they way individuals construct knowledge is premised on their personal history and its influence on how the individual has constructed their knowledge (Billett 1998). However, it is unlikely, for instance, that occupation, health and safety principles learnt in a meat processing plant would readily transfer to those in a viticulture operation. Conversely, it is perhaps more likely that specific procedures of work practice (e.g. using a word processor, filing documents) would transfer across instances of clerical work practice. However, and in qualification, how those specific procedures are to be used and judged in particular circumstances will not be uniform and variations in practice that may even cause problems with the transfer of these specific procedures.

The concern about the potential specificity of learning outcomes leads to a consideration of how vocational education provisions can assist transferring students to different kinds of work practice either within the workplace or others. The ability to provide learning within diverse circumstances in different kinds of workplace settings, supported by deliberate instruction aimed at developing understanding and procedures able to be applied broadly is the ideal, but rarely available situation. Failing this, instructional strategies that assist the development of knowledge in one circumstance and then provide instances of other ways in which the tasks can be done as well as understanding about the procedures of the how the vocational knowledge is to be applied may well be the best substitute. Whatever approach is possible or adopted, the key consideration is for educational goals and instructional processes to find ways of maximising the prospect of transferring the learners' knowledge.

So, in sum, enterprises views can be summarised as wanting the shift towards an enterprise focus to:

- go further;

- $\quad$ involve more negotiation with providers; 
- $\quad$ be enterprise-driven; and (yet)

- retain national certification.

Industry representatives were concerned that this shift would lead to the:

- erosion of portable qualifications and industry goals;

- specificity of course content and goals;

- danger of fragmented curriculum; and

- potential for securing long-term goals of skillfulness.

The evidence provided here also suggests that an enterprise focused approach may result in:

- low levels of course completion;

- enterprise specific curricula;

- $\quad$ some individuals' career aspirations being frustrated; and

- little in way of strategic concerns associated with a skilled workforce being met.

Importantly, there is little evidence to suggest that merely placing an emphasis on enterprises will enhance the quantum and quality of vocational education. The failure of the 'industry' focus to realise this goal seems to have been instrumental in the shift to a focus on enterprises. Yet the evidence from the enterprises in the three regions makes achieving this goal seem wholly optimistic. What the enterprises in this study suggested when asked what would precipitate an enhanced expenditure on training, the commonest response was to say external legislated demands (particularly in the food processing industry). Other evidence is added which indicates the reduction not only in apprentice intakes (STB 1995), but where entry level training is increasing it is of the short duration traineeship kind (STB 1995). Therefore, the assumption that simply making vocational education provisions focussed upon and tailored to the needs of enterprises, will lead to an enhancement in their commitment is ill-founded. This is not to simply fault enterprises for failing to meet expectations, but rather to suggest that the policy focus under which such an arrangement was formulated may be misguided.

\subsection{Reconciling the demand side}

In the aggregated data, (Table 1) it was clear that client groups' needs exhibited both areas of commonality and difference. A key concern is how best to reconcile the different needs from the data above. In sum, commonality across all groups was associated with:

- flexibility, relevance and currency of courses; 
- competence of teachers; and

- $\quad$ need for nationally accredited courses.

These considerations reflect both process and outcome concerns, but with a strong emphasis on the quality of course provisions - supply side factors.

In sum, commonality between/among comprised:

- the need for appropriate infrastructure to support a comprehensive VET system [industry and students];

- meeting individuals’ needs [enterprises, community and students];

- wider enterprise participation in vocational education and, in particular, by small business [industry and communities];

- improving business outcomes [enterprises and community]; and

- realising individuals’ employment and career goals [community and students].

In sum, differences included:

- enterprises want outcomes tightly aligned to their activities and goals;

- students want outcomes associated with employment, but not so specific as to inhibit career advancement or access to higher levels of education;

- industry wants outcomes associated with adherence to national core curriculum documentation, certification and improvements in the quantum and quality of vocational education; and

- regions want outcomes associated with enterprises’ and individuals’ development.

Taking both the similarities and differences outlined above, an approach to reconciling the needs of the client groups is now advanced. This approach comprises decision-making that is both centred and de-centred, and focussing on the outcomes proposed by industry and enterprises, and using an emphasis on instructional process most likely to provide individuals with the kinds of robust transferable outcomes that they desire. A key change to the existing arrangements is to conceptualise the national coherence within vocational education provisions upon 'occupations' rather than 'industry'. Four reasons for considering this option are: 
1. providing coherence through vocations which reflect skillfulness (vocational knowledge), individuals' aspirations (career pathways within a vocation) and enterprises (access to relevant vocations);

2. enhancing opportunities for collaborative and voluntary arrangements, and associations premised on vocational activities; and

3. separating curriculum practices from the changing and highly contested industrial relations environment,

4. providing flexibility for employment through the vocational recognition.

The shift vocational education to an occupational focus of concern provides a less contested domain of activity and one that will be more compatible with a broader set of interests of the entire client groups. This is not to say that industrial relations interests would be excluded from deliberations about occupational intent and content. Rather, these interests will need to be negotiated and balanced with other interests.

What follows outlines the four sets of interests proposed as levels of input into curriculum development for vocational education.

\section{Occupational level}

From the above, it is proposed that occupations be used as the key organising concept and a basis by which to reconcile the inclusive set of clients' needs of vocational education through the contributions of:

- an occupational basis for organising vocational education curricula stranding, negotiated at national and regional levels;

- identification of broad statements of educational intent (goals and aims);

- identification of recommended course content;

- identifying career pathways for and options within vocational education; and

- accrediting a national certification process (such as external examinations).

So the central function is to provide general (not specific and highly detailed) statements of intent at the aims and goal level of formulation, identify content appropriate for the occupation, potentially in strands that make distinct different parts of the occupational sector.

\section{Enterprise level}

Enterprises desire for programs that specifically meet their needs will be addressed through: 
- provision of vocationally-based courses, customised to approximate vocational activities within enterprises;

- the negotiation/refinement of both content and outcomes;

- support and facilitation to participate in vocational education and/or develop a capacity to provide quality 'in-house programs.'

\section{Regional level}

Each region has needs of vocational education that are different. For regions, needs include:

- local planning;

- local facilitation of courses to address the needs of local enterprises, groups of enterprises, and local providers of vocational education programs;

- tailoring of provisions to enterprise needs; and

- negotiation of content and refinement of outcomes.

\section{Individual level}

From the finding, individuals' needs will be addressed through:

- access to courses which retain national certification;

- $\quad$ have career pathways identified;

- provisions which address local enterprise needs;

- $\quad$ accessible and supportive teachers who address individual students’ needs;

- a strong focus on the development of skills that have a transferable base; and

- information about courses.

The majority of students (prospective, current and past) report engaging in vocational education for employment-related reasons. However, these were usually more than just gaining employment. Often, they identified clear strategic goals for their participation in vocational education. To realise these needs, a focus upon both process and outcomes is required, as foreshadowed at the occupational level. Structures need to be identified that reflect the diversity of likely occupational pathways with outcomes broad enough to provide certification. The most important consideration is the development of transferable knowledge for students. Both intents and content stated broadly at a local level can be tailored to the needs of local enterprises. However, to assist the best prospect for robust outcomes it is proposed that students' learning be focussed on the development of transferable occupational knowledge. Therefore, the instructional 
process will be required to include processes for reflecting upon how occupational tasks are undertaken in a particular environment and the provisions for options of how this skill might be applied in other circumstances. Varied workplaces experiences are desired to be provided to assist in the development of this robust knowledge. Accreditation processes will need to take into account the need for instruction processes that account for such requirements. At the occupational level it will be necessary for these requirements for the accreditation to be established.

The curriculum development process which aims to address and reconcile these needs comprises at the national level, the identification of broad statements of intent (aims and goals) and recommended content. The statements of intent are refined further in the form of objectives at the local (regional) level where the suitability of content can also be negotiated, as considerations about how best this content can be taught and learnt. At this level, compensatory measures can be implemented to enrich experiences that will be inadequate in either the educational institution or the workplace. Equally, at this level the key focus of learning for transfer is required and appropriate strategies adopted for learners to secure this knowledge.

\section{$\underline{5.3 \quad \text { Supply-side considerations }}$}

From the findings of this study it seems the supply-side of vocational education cannot be wholly ignored. Three key supply side issues are referred to here briefly. These are (a) a broader role for vocational educators; (b) consideration co-operation over competition and (c) the role of TAFE as the key provider with VET.

(a) broader role for vocational educators

The last decade has seen a reduction in the scope of tasks undertaken by vocational educators, and simultaneously a reduction in their discretion (Billett et al in press). What is clear in the data presented in the investigation is that the shift to an enterprise focus demands a wider role for teachers as well a higher discretion in their practice. Beyond just addressing enterprise needs, the local and de-centered model of vocational education proposed above, requires the application of a wide range of professional practice and a corresponding broader set of roles for vocational educators. This broadening of the role was advocated by all client groups to meet their needs. These roles are:

- Developer. Consultant;

- Curriculum Developer;

- Instructor; 
- Advocate and supporter of learners; and

- Policy

Vocational educators are required to play a wider, more diverse and complex role in meeting and reconciling the needs of the four client groups. In particular, planning for curriculum provisions and maximising the prospect for transfer are roles that require highly developed educational and instructional skills. Central to meeting concerns associated with the robustness of knowledge are foci on process concerns. In particular, the use of instructional processes focuses on developing robust vocational knowledge. This role should legitimately place teachers in at the front of curriculum decision-making and leadership and present novel challenges about the nature of professional practice. The preparedness of vocational educators will be essential to the quality of vocational education provisions.

\section{(b) co-operation or competition}

The market-based approach may address the needs of large enterprises and provide some competition in metropolitan communities, but it seems little else. This is particularly the case where 'thin markets' (Anderson 1996, Burke 1995) exist as was evident in two regions in this study and is probably the case in most non-metropolitan regions of Australia. Yet even where training markets exist, there is evidence of a lack of ability to meet the needs of small enterprises or small groups of individuals. It was the more market-driven Food Processing sector that suffered the greatest problems in this respect. In particular, the failure to secure high levels of course completion and certification disadvantages those students who are enrolled through enterprise-based arrangements. Regional initiatives that emphasise mutuality of needs between clusters of small enterprises engaged in the same vocational practice may offer a basis for meeting the needs of small and remote enterprises in a market-premised system. However, these

arrangements are likely to require some degree of support. Models of facilitation and support are the ones that currently provide any evidence of an increase in enterprise interest in entry level training.

Linking current constraints to past experiences, it seems that facilitation and support for enterprise participation in vocational education, as much as market-based provisions are likely to be required to assist enterprises with participation in vocational education and to establish a capacity to develop the skillfulness of workers in their workplaces. The only appreciable increases in enterprise sponsorship of entry level training have occurred when government 
support and facilitation was available (Billett et al 1997). This type of approach might run counter to market-based principles that are guiding current policy developments in vocational education. However, what is most desired, fidelity to these principles or a robust vocational education system.

(c) TAFE as the key provider with VET.

A clear but unintended outcome of this investigation was evidence from all four client groups about the high quality of TAFE provisions. The findings suggest that rather than seeking to place more pressure on TAFE provisions they should play an enhanced wide and more valued role in vocational education provisions. TAFE, in particular, seems central to the maintenance and development of vocational education in non-metropolitan regions. Whereas enterprises do appear to be able to perform the strategic role, that has been set for them, TAFE seems to offer the basis for a strong and widely geographically distributed provision about to realise important strategic goals within vocational education. The contribution of the institution at the local level should not be underestimated in its potential to meet individual, regional, industry and enterprise needs. The diverse requirements of these client groups mean that the intents and content have to e negotiated at the local level. Moreover, process considerations in terms of securing knowledge that is transferable, will fall to the instructional capacities of organisations such as TAFE institutes and their teachers.

\section{Conclusion}

In conclusion, while this study was limited in scope, it alerts us to the importance of the identification and reconciliation of the diverse sets of needs that comprise the demand side. For these needs to be fully met, a more inclusive set of interests need to be recognised and included in deliberations about the intents, content and provisions of vocational education. The demands of industry and enterprise alone while forming important sets of interests, do not themselves constitute the demand side. In particular, industry concerns for content and outcomes that have a broader application than enterprise needs are in some ways considerate of the needs of individuals and regions. Perhaps the greatest tension resides in the conflict between the enterprise demand for highly specific outcomes and content and those that emphasise broadly more applicable goals required by industry and individuals. The concept of occupation is proposed as means of providing national coherence, pathways for career paths and a base for national certification. The local level of decision-making and curriculum development appears to be significant keys to reconciling needs through the refinement of curriculum intents and content. Moreover, the 
process focus within instruction to develop transferable knowledge is likely to be highly essential for not only individuals but the other client groups. Importantly, there is little evidence to suggest that simply placing an emphasis on enterprises will enhance the quantum and quality of vocational education.

\section{References}

Allen Consultancy Group, 1994a, Successful reform: Competitive skills for Australia and Australian enterprises, Australian National Training Authority, Brisbane.

Allen Consultancy Group, 1994b, Establishing an effective Australian training market, Office of Training and Further Education, Melbourne.

Anderson, D, 1996, 'The training market reforms and their impact on the vocational education and training system,' in Selby Smith, C \& F. Ferrier, (eds), The Economic Impact of Vocational Education and Training, Monash University-ACER Centre for the Economics of Education and Training, AGPS, Melbourne.

Australian National Training Authority (ANTA) 1998, National Strategy for Vocational education and Training 1998-2003: Brisbane, ANTA 20 March 1998.

ANTA 1996 Developing the training market of the future, A consultation paper, ANTA, Brisbane

Billett, S, Cooper, M, Hayes, S \& Parker, H. 1997, VET policy and research: Emerging issues and changing relationships. Office of Training and Further Education, Melbourne Victoria.

Billett, S. 1998, The transfer problem: distinguishing between levels of social practice. Australian and New Zealand Journal of Vocational Education Research vol 6, No 1 pp.1-26.

Billett, S, McKavanagh, C, Beven F, Hayes, S, Angus, L, Seddon, T, Gough J \& Robertson I (in press) The CBT Decade: Teaching for Flexibility and Adaptability. Nationl Centre for Vocational Education Research. Adelaide. South Australia.

Burke, G 1995, 'Some aspects of the economic evaluation of vocational education and training', in Ferrier and Selby-Smith (eds), The economics of education and training, AGPS, Canberra.

Buttery, E \& Buttery, A 1994, The provision of small business support services in Queensland: The small business person's perspective, James Cook University, Townsville.

Callus, R 1994, 'Research priorities in small business,' A discussion paper from the Research Priorities in Vocational Education and Training Conference, NCVER, Adelaide, pp.1531. June 1994

Chapman, B 1997, The role of government in post-compulsory education: An economic primer, Centre for Economic Policy Research, Research School of Social Sciences, ANU, Canberra.

Employment Department, 1993, Government announcement of Regional and Urban policy. London: Employment Department.

Dawkins, J 1988, Industry Training in Australia: The Need for Change. Canberra, Australian Government Publishing Services.

Guthrie, J \& Barnett, K 1996 Training and enterprise bargaining, NCVER, Adelaide.

Kearns, P \& Assoc. 1997, Flexible delivery of training, A research review, NCVER, Adelaide

National Training Board. 1992, National Competency Standards - Policy and Guidelines. Canberra: Australian Government Publishing Services.

NCVER Graduate Destination Survey. National centre for Vocational education Research, Adelaide

Resnick L B, Pontecorvo C \& Saljo R 1997, (eds) Discourse, tools and reasoning: Essays on Situated Cognition. Springer, Berlin. 
Robinson C \& Kenyon R 1998 (eds) The Market for Vocational Education and Training. Adelaide: National Centre for Vocational Education Research:

Rogoff, B., \& Lave, J. (eds). 1984, Everyday cognition: Its development in social context. Cambridge, Mass.: Harvard University Press.

Schofield, K \& Associates 1996, Think local and compete, Australian National Training Authority, Brisbane.

State Training Board, Victoria 1995b, Trends in Vocational Education and Training, STB, Melbourne.

VEETAC Working Party on the Recognition of Training. 1992, Nationally Recognised Training bringing it all together. Australian Government Printing Service. Canberra. 